\title{
Severe Hyperphosphatemia and Hypocalcemia Caused by Bowel Preparation for Colonoscopy Using Oral Sodium Phosphate in End-Stage Renal Disease
}

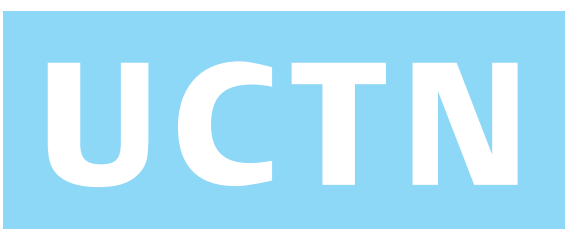

Bowel preparations containing oral sodium phosphate have gained increased favor among gastroenterology endoscopists in preference to the traditional polyethylene glycol, likely due to greater patient tolerability and improved cleansing and compliance [1]. Despite the availability of reports in the literature concerning life-threatening metabolic and cardiac abnormalities associated with the use of oral sodium phosphate in patients with renal insufficiency, less than half of respondents in a recent survey among gastrointestinal endoscopists reported its exclusion in this patient population [2]. We report two cases of severe hyperphosphatemia and secondary hypocalcemia due to administration of an oral sodium phosphate-containing bowel preparation in patients with chronic renal insufficiency.

The first patient, a 51-year-old woman with end-stage renal disease requiring peritoneal dialysis, was evaluated for generalized weakness, perioral tingling, elicitable Chvostek's sign, and a prolonged QT interval. The patient had ingested two 45$\mathrm{ml}$ doses of Fleet's Phospho-Soda solution the previous night, in preparation for a screening colonoscopy. Laboratory evaluation revealed abnormal levels of calcium and phosphate in comparison with baseline values (Figure $\mathbf{1}$ ). Clinical symptoms and laboratory abnormalities of hypocalcemic tetany resolved rapidly after the patient received intravenous calcium and peritoneal dialysis. The patient subsequently underwent colonoscopy without any complications and continued to be asymptomatic on follow-up.

The second patient was a 57-year-old man with diabetes mellitus and chronic renal insufficiency who presented with hematochezia. Laboratory values on admission were unremarkable except for a serum creatinine of $2.1 \mathrm{mg} / \mathrm{dl}$. At 2 days after ingesting two doses of $45 \mathrm{ml}$ of oral sodium phosphate for a colonoscopy, his metabolic profile demonstrated serum calcium and phosphate of $6.5 \mathrm{mg} / \mathrm{dl}$ and $16.9 \mathrm{mg} /$ $\mathrm{dl}$, respectively (Figure $\mathbf{1}$ ). He remained

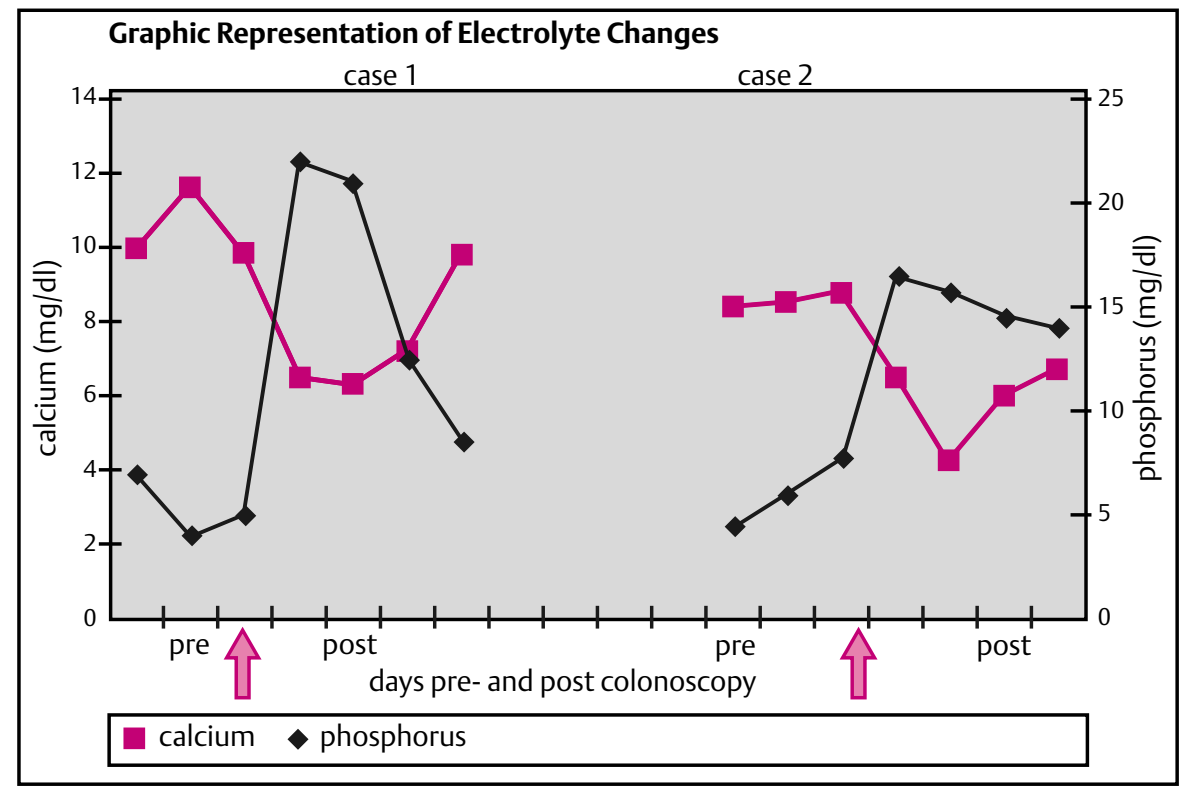

Figure 1 Graphic representation of electrolyte changes.

asymptomatic and received oral calcium acetate to bind phosphate. The patient was discharged in a stable condition with serum calcium and phosphate of $6.7 \mathrm{mg} /$ $\mathrm{dl}$ and $14.4 \mathrm{mg} / \mathrm{dl}$, respectively. No follow-up information was available.

Similar abnormalities in serum calcium and phosphate, associated with oral sodium phosphate ingestion, have been reported in the absence of renal insufficiency. This may, however, be related to the dosage of oral sodium phosphate administered (greater than $90 \mathrm{ml}$ ) or to impaired bowel motility leading to prolonged intestinal transit time [3]. A 45$\mathrm{ml}$ bottle of oral sodium phosphate contains approximately $6 \mathrm{~g}$ of inorganic phosphate, while a person with normal renal function can handle an intake of phosphate up to $4 \mathrm{~g}$ over a 24-hour period, due to reduced proximal tubular reabsorption of phosphate [4]. A rise in serum phosphate is thought to be the primary etiology of hypocalcaemia in these patients [5].
Previously published literature does not report the magnitude of renal insufficiency that would raise concern about the renal ability to handle the phosphate load present in the oral sodium phosphate. Based on available information about phosphate metabolism, and the kinetics of renal handling of phosphate, one can postulate that a creatinine clearance $\leq 50 \mathrm{ml} / \mathrm{min}$ or serum creatinine of $>2.0 \mathrm{mg} / \mathrm{dl}$ may lead to significant hyperphosphatemia following the ingestion of a single dose of oral sodium phosphate containing a phosphate load of $6 \mathrm{~g}$. Careful attention should be paid when selecting bowel-cleansing preparations for colonoscopy in patients with renal insufficiency.

\section{R. Mishra1, D. Kaufman², J. Mattern III'2, S. K. Dutta ${ }^{2}$ \\ ${ }^{1}$ Division of Internal Medicine, Cleveland Clinic Foundation, Cleveland, Ohio, USA \\ 2 Division of Gastroenterology, Sinai Hospital of Baltimore/Johns Hopkins University School of Medicine, Baltimore, Maryland, USA}




\section{UCTN}

References

${ }^{1}$ Cohen SM, Wexner SD, Binderow SRet al. Prospective, randomized, endoscopic-blinded trial comparing precolonoscopy bowel cleansing methods. Dis Colon Rectum 1994; 37: 689-696

${ }^{2}$ Chan A, Depew W, Vanner S. Use of oral sodium phosphate colonic lavage solution by Canadian colonoscopists: pitfalls and complications. Can J Gastroenterol 1997; 11: 334-338

${ }^{3}$ Fass R, Do S, Hixson LJ. Fatal hyperphosphatemia following Fleet PhosphoSoda in a patient with colonic ileus. Am J Gastroenterol 1993; 88: 929-932
${ }^{4}$ Vukasin P, Weston LA, Beart RW. Oral Fleet Phospho-Soda laxative-induced hyperphosphatemia and hypocalcemic tetany in an adult: report of a case. Dis Colon Rectum 1997; 40: 497-499

${ }^{5}$ Wiberg JJ, Turner GG, Nuttall FQ. Effect of phosphate or magnesium cathartics on serum calcium. Observations in normocalcemic patients. Arch Intern Med 1978; 138: $1114-1116$

\section{Corresponding Author}

\section{S. K. Dutta, M.D.}

Division of Gastroenterology Department of Medicine Hoffberger Professional Building 2435 West Belvedere Avenue, Suite 51 Baltimore, MD 21215

USA

Fax: $\quad+1-410-601-5757$

E-mail: rajnishroger@yahoo.com 